\title{
KONSEP MOTION GRAPHICS PENGENALAN LAYANG-LAYANG SEBAGAI BUDAYA BANGSA
}

\author{
Betha Almanfaluthi ${ }^{1}$, Juniar ${ }^{2}$ \\ Institut Teknologi dan Bisnis Kalbis ${ }^{12}$
}

\begin{abstract}
Abstrak. Layang-layang adalah salah satu permainan tradisional dunia yang memiliki sejarah sangat panjang. Usia permainan yang sudah tua membuat layang-layang mengalami perkembangan yang sangat beragam di berbagai belahan dunia. Indonesia menjadi salah satu negara yang memiliki tradisi layang-layang. Jenis dan bentuk layang-layang yang ada di Indonesia sangat variatif. Indonesia yang begitu kaya akan budaya daerah tentu menjadi faktor hadirnya ragam layang-layang. Berkurangnya lahan bermain ditambah dengan perkembangan teknologi yang menyediakan banyak permainan digital membuat permainan ini mulai ditinggalkan. Penelitian ini bertujuan untuk membuat konsep motion graphics untuk mengenalkan layanglayang sebagai budaya bangsa yang harus dibanggakan dan dilestarikan. Dengan pendekatan metode analisis sintagmatik dan paradigmatik, penelitian ini menghasilkan konsep motion graphics yang menceritakan bahwa ciri khas bentuk dan desain layang-layang yang ditemukan di beberapa daerah di Indonesia banyak dipengaruhi oleh fungsi dari layang-layang itu sendiri. Konsep perancangan motion graphics juga menonjolkan nilai-nilai positif dari permainan layang-layang yang dapat ditanamkan pada diri anak-anak, yakni sabar, gigih, mau kerja sama.
\end{abstract}

Kata Kunci: motion graphics, layang-layang, tradisi, sintagmatik, paradigmatik

\begin{abstract}
Kites is one of the world's traditional games that has a very long history. This old game makes kites have a very diverse in progress in all parts of the world. Indonesia is one of the countries that have a kite tradition. The types and forms of kites in Indonesia are very varied. Indonesia, which is rich in local culture, is certainly one of factors in the variety of kites. The reduced playing ground coupled with the development of technology that provides digital games makes this game begin to be abandoned. This study aims to build the concept of motion graphics to introduce kites as a national culture that must be proud of and preserved. With the approach of syntagmatic and paradigmatic analysis methods, this research develops the concept of motion graphics which tells us that the characteristics of the shape and design of kites found in several regions in Indonesia are much influenced by the function of the kite itself. The concept of motion graphics design also highlights the positive values of kites game that can be instilled in children which are patience, perseverance, willing to work together.
\end{abstract}

Keywords: motion graphics, kites, tradition, syntagmatic, paradigmatic

Correspondence author: Betha Almanfaluthi, betha.almanfaluthi@kalbis.ac.id, Jakarta, Indonesia 


\section{Pendahuluan}

Layang-layang adalah salah satu permainan tradisional yang dimainkan di berbagai penjuru dunia. Permainan ini dimainkan oleh berbagai kalangan usia mulai dari anak-anak hingga dewasa. Sejarah panjang layang-layang membuat permainan ini memiliki jenis dan bentuk yang sangat beragam. Mengingat sejarah panjang kehadiran layang-layang dan begitu luas penyebarannya, asal-usul layang-layang ini secara tepat masih menjadi teka-teki.

Bukti yang tercatat di dalam dokumen sejarah menyebutkan bahwa layang-layang bermula dari Cina sekitar 2500 tahun yang lalu dan kemudian menyebar ke negara-negara lain (Mikkolainen). Namun di tahun 2002 terdapat temuan baru yang memungkinkan klaim sebagai layang-layang pertama bisa diambil alih meskipun secara ilmiah belum dapat dibuktikan. Temuan tersebut adalah ditemukannya sebuah lukisan pra sejarah di salah satu gua di pulau Muna, Sulawesi Tenggara berupa gambar seseorang yang sedang menerbangkan layang-layang. Keabsahan mengenai usia lukisan tersebut belum dapat dipastikan. Para peneliti belum dapat menyimpulkan berapa usia lukisan tersebut.

Layang-layang yang terdapat di lukisan gua tersebut diyakini merupakan layang-layang yang sama dengan tradisi layang-layang Muna yang dilestarikan turun temurun hingga sekarang yaitu layang-layang kaghati. Dalam Bahasa setempat, kaghati berarti daun. Daun yang digunakan untuk membuat layang-layang adalah daun kolope yang sudah kering. Penggunaan daun kolope inilah yang memperkuat dugaan Wolfgang Bieck bahwa material di tradisi layanglayang kaghati adalah bahan-bahan sederhana, tidak seperti material layang-layang di Cina yang menggunakan kain.

Terlepas dari kemungkinan mendapatkan status sebagai negara tempat asal-usul layang-layang pertama di dunia, penemuan ini membuktikan bahwa tradisi layang-layang di Indonesia khususnya di Sulawesi Tenggara merupakan salah satu tradisi layang-layang tertua di dunia. Tidak hanya di Sulawesi, penyebaran permainan layang-layang di tanah air meluas hingga ke pulau Bali, Jawa dan Sumatera.

Sama halnya dengan permainan tradisional lainnya, layang-layang kini sudah jarang dimainkan terlebih di kota-kota besar. Berkurangnya lahan bermain ditambah dengan perkembangan teknologi yang menyediakan banyak permainan digital membuat permainan ini mulai ditinggalkan. Eksistensi permainan layang-layang kini seakan mengandalkan festival yang hanya ada sesekali dalam tiap tahun.

Upaya mempertahankan budaya layang-layang di Indonesia dilakukan oleh komunitas pecinta layang-layang dan didirikannya museum layang-layang yang digagas oleh salah satu pionir komunitas tersebut, Endang Puspoyo. Komunitas ini kerap mengikuti festival layanglayang baik di dalam maupun di luar negeri. Layang-layang tradisional Indonesia sering menjadi perhatian karena layang-layang Indonesia memiliki ciri khas dan bahkan beberapa kali menjadi juara di ajang perlombaan layang-layang. Ciri khas layang-layang yang ada di Indonesia tidak lepas dari beragam tradisi dan budaya yang memengaruhi bentuk layang-layang yang ada di tiap daerah (Puspoyo).

Terdapat beberapa penelitian dan publikasi sebelumnya mengenai tradisi layanglayang, yang pertama ada sebuah penelitian oleh I Wayan Wahyu Wira Udytama dengan judul Perlindungan Hukum Terhadap Eksistensi Layang -Layang Tradisional Bali Sebagai Penguatan Pariwisata Budaya. Hasil penelitiannya menunjukkan bahwa ada upaya yang dilakukan oleh desa Pakraman di Bali untuk melindungi layang-layang tradisional sebagai asset budaya Bali dengan memberikan kesempatan untuk mensakralkan layang-layang dibuat.

Penelitian lain yang meneliti seputar layangan tradisional di Indonesia adalah peneitian berjudul Layang-Layang Bebean Di Desa Ungasan, Kecamatan Kuta Selatan, Kabupaten Badung 
oleh Meisaroh et al. dari Jurusan Pendidikan Seni Rupa Universitas Pendidikan Ganesha Singaraja. Dalam penelitiannya menjelaskan proses pembuatan layang-layang dan makna warna pada layang-layang bebean merupakan warna yang menyimbolkan Tridatu yaitu merah sebagai Dewa Siwa, Hitam sebagai Dewa Wisnu, dan Putih sebagai Dewa Brahma.

Berdasarkan uraian di atas, perlu satu upaya yang dilakukan untuk mengenalkan layanglayang dengan cara yang bebeda, mengingat sudah jarang yang memainkan permainan tradisional ini. Oleh karena itu dalam penelitian dibatasi pada konsep seni untuk merancang motion graphics yang memperkenalkan layang-layang sebagai salah satu budaya bangsa yang patut dibanggakan dan harus dilestarikan. Penelitian ini dapat memberikan manfaat akademis dan praktis. Manfaat di bidang akademis yakni dapat menambah referensi dalam menyiapkan sebuah karya desain yang berkaitan dengan tradisi sebuah bangsa. Sedangkan manfaat di bidang praktis adalah dapat digunakannya rancangan motion graphics pengenalan layang-layang sebagai budaya bangsa ini sebagai materi penyampaian cerita dan informasi dalam bentuk konten multimedia. Konten ini dapat dimuat pada website dan media sosial.

\section{Metode}

Penelitian ini dilakukan dengan metode kualitatif dengan pendekatan analisis sintagmatik dan paradigmatik yaitu penelitian yang dilakukan untuk dapat memilih obyek-obyek penyusun visual yang semula jika dilihat secara individu belum menjadi penanda sebuah maksud dapat dibaca sebagai sebuah makna kolektif. Sintagmatik pada bahasa visual melihat relasi obyek-obyek satu sama lain dalam sebuah tampilan. Pada level paradigmatik berhubungan dengan konteks, yakni konteks ditentukan oleh keberadaan obyek-obyek yang muncul dalam satu tampilan visual (Collington). Pendekatan analisis ini masih berkaitan erat dengan ilmu semiotika yakni ilmu yang mempelajari tanda. Tanda-tanda yang akan dikaji adalah tanda-tanda visual yang diamati dan dijadikan bagian dari konten penyusun motion graphics. Pengumpulan data seputar layang-layang Indonesia dilakukan melalui studi pustaka ke Museum LayangLayang Indonesia yang berlokasi di J. H. Kamang No.38, Pondok Labu, Cilandak, Jakarta Selatan.

\section{Pembahasan}

Layang-Layang

Selain menjadi alat permainan, layang-layang memiliki beberapa kegunaan. Seiring dengan perkembangan zaman dan kondisi yang dialami, layang-layang dimanfaatkan untuk berbagai macam kegunaan. Material yang mudah didapat dan pembuatan yang relatif mudah membuat layang-layang menjadi alternatif untuk memenuhi kebutuhan-kebutuhan tersebut. Kegunaan layang-layang antara lain untuk kegunaan ritual, layang-layang digunakan para warga pedesaan untuk mengucap syukur atas panen yang dihasilkan. Pada adat tertentu hasil panen merupakan pemberian para dewa. Di Bali pun juga melakukan hal yang sama, menerbangkan layang-layang adalah bentuk rasa terima kasih kepada dewa.

Di catatan sejarah tentang penggunaan layang-layang pertama di zaman dinasti Han, layang-layang digunakan untuk mengukur jarak yang harus ditempuh pasukan untuk menuju wilayah musuh. Di belahan dunia lain, layang-layang juga digunakan sebagai alat bantu nelayan untuk memancing. Di Eropa dan Amerika Serikat layang-layang juga pernah digunakan untuk kebutuhan penelitian. 


\section{Museum Layang-Layang Indonesia}

Indonesia memiliki sebuah museum khusus mengenai layang-layang, yaitu Museum Layang-Layang Indonesia yang terletak di Jalan H Kamang No.38, Pondok Labu, Jakarta Selatan. Museum ini didirikan oleh seorang pecinta layang-layang, Endang W Puspoyo. Awalnya Endang hanya ingin mengoleksi layang-layang sebagai hobi. Hobi ini dilakukan dengan bantuan temantemannya sesama pecinta layang-layang. Seiring dengan seringnya berkumpul dengan sesame pecinta layang-layang maka Endang dan teman-temannya membentuk sebuah komunitas pecinta layang-layang. Setelah koleksi layang-layang terkumpul banyak maka Endang memutuskan untuk membuat sebuah museum yang memajang koleksinya.

Membuka museum layang-layang dan membentuk komunitas pecinta layang-layang adalah upaya dari Endang untuk melestarikan salah satu permainan tradisional yang sangat kental dengan budaya Indonesia.

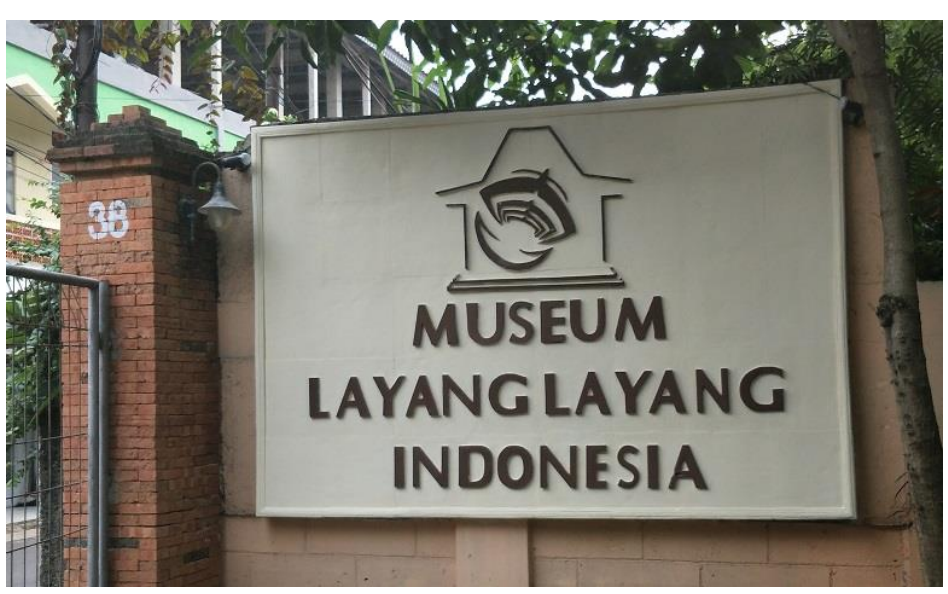

Gambar 1 Sign Museum Layang-Layang Indonesia

\section{Layang-Layang Tradisional Indonesia}

Di Indonesia telah ditemukan sebuah lukisan pra sejarah di salah satu gua di pulau Muna, Sulawesi Tenggara. Dalam lukisan itu terlihat ada gambar seseorang yang sedang bermain layang-layang. Layang-layang yang terdapat di lukisan gua ini diyakini merupakan jenis layanglayang yang sama dengan layang-layang tradisi Muna yang dilestarikan turun temurun hingga sekarang yaitu layang-layang kaghati. Dalam bahasa setempat, kaghati berarti daun. Daun yang digunakan untuk membuat layang-layang adalah daun kolope yang sudah kering.

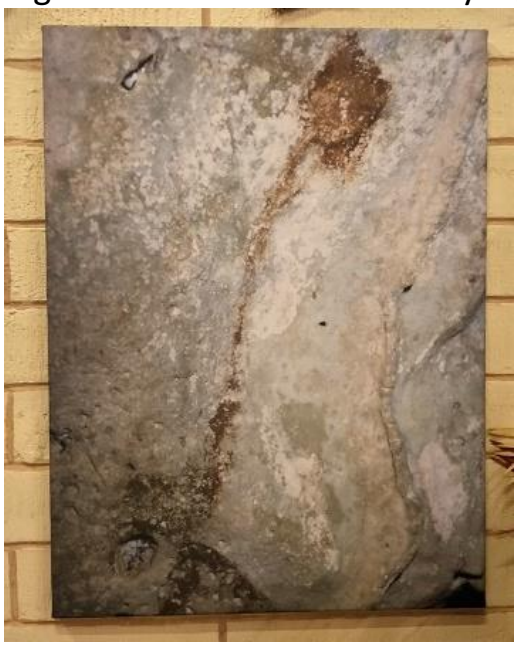

Gambar 2 Foto lukisan gua di salah satu gua di pulau Muna, Sulawesi Tenggara 


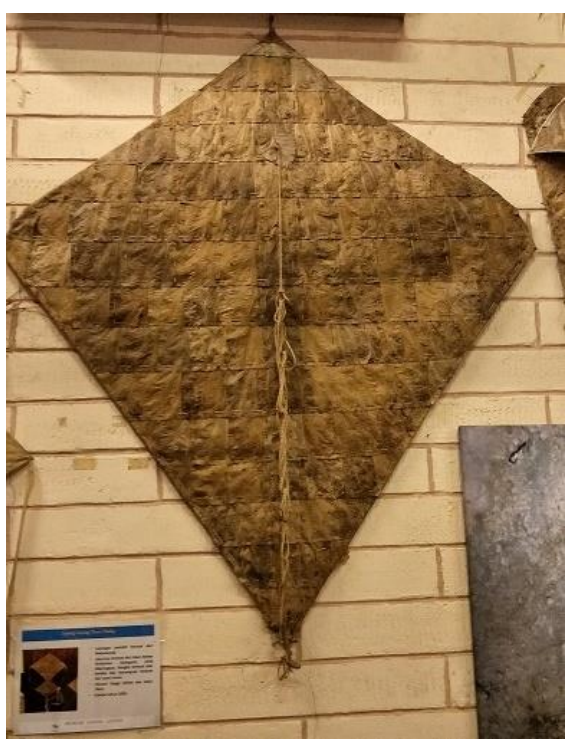

Gambar 3 Layang-layang kaghati

Di Aceh terdapat jenis layang-layang khas yang bentuknya menyerupai seekor elang dalam posisi terbang yang sedang melebarkan sayapnya. Nama jenis layang-layangnya adalah kleung. Kata kleung ini memiliki arti Elang dalam bahasa Aceh. Asal mula tradisi memainkan layang-layang kleung ini di Aceh ini merupakan salah satu bentuk permainan yang melepaskan rasa lelah masyarakat setempat atas hasil kerja keras selama bertani dan bergembira atas hasil panen padi.

Layang-layang kleung adalah salah satu jenis layang-layang yang dipertandingkan dengan peraturan harus menerbangkan layang-layang setinggi mungkin namun harus sejajar dengan posisi kepala pemainnya. Layaknya burung elang, layang-layang kleung memiliki bagianbagian yang dimiliki burung yaitu kepala, punggung, pinggang, sayap, dan ekor. Kerangka pada layang-layang kleung mengikuti struktur pesawat yang juga terinspirasi dari anatomi burung. Rangka layang-layang kleung pada umumnya terbuat dari bambu. Bambu yang digunakan adalah yang sudah berusia tua karena lebih lentur dan tahan terhadap hembusan angin yang kencang.

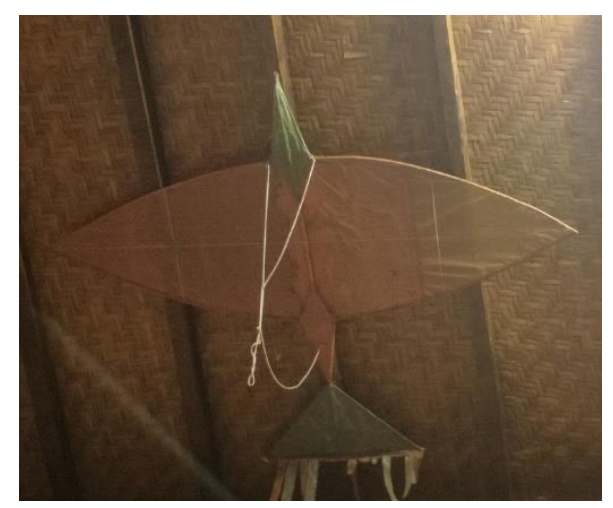

Gambar 4 Layang-layang kleung

Ukuran layang-layang kleung lebih besar dibanding layang-layang yang biasa kita lihat yang dimainkan oleh anak-anak. Ukuran panjang dan lebar keseluruhan layang-layang kleung masing-masing bisa mencapai 2 meter. Ukuran layang-layang yang besar inilah yang menjadikan permainan ini biasa dimainkan oleh orang dewasa. Dalam menerbangkannya pun dibutuhkan 
kerja sama hingga 3 orang. Anak-anak yang diajak bermain biasanya menjadi bagian dari kelompok yang mendapatkan tugas untuk mengulur dan menggulung benang sesuai instruksi dari pemain dewasa yang mengendalikan layang-layang tersebut.

Sesuai tradisi, pada zaman dulu layang-layang kleung dimainkan pada saat selesai musim panen hingga akan dimulainya musim tanam. Kondisi persawahan menjadi rata dan kering sehingga menjadi lapangan yang luas dan sangat mendukung untuk memainkan layanglayang. Situasinya di zaman sekarang berbeda, layang-layang kleung tidak lagi dimainkan hanya pada musim panen mengingat lahan persawahan yang sudah tidak seluas dulu akibat perubahan fungsi lahan yang dijadikan kawasan pemukiman dan pusat perbelanjaan. Sehingga saat persawahan kering belum tentu kondisinya mendukung untuk menerbangkan layang-layang. Kini lokasi untuk memainkan layang-layang biasanya berupa lapangan yang memang disediakan pemerintah untuk dijadikan lapangan olah raga bagi masyarakat sekitar. Terkadang layanglayang kleung juga terlihat dimainkan di pinggir jalan utama yang memiliki lahan yang cukup untuk menerbangkan layang-layang. Permainan layang-layang kleung saat ini lebih sering dimainkan saat memperingati hari-hari tertentu atau memang diadakan lomba tanpa lagi mengacu pada musim panen.

Masyarakat Lampung juga memiliki layang-layang yang khas daerahnya yaitu layanglayang Siger. Siger adalah nama mahkota pengantin wanita Lampung. Layangan ini memiliki bentuk yang agak persegi namun memiliki sudut yang agak melengkung sehingga bentuknya hamper bulat dengan ada bagian runcing sedikit di ujung atas. Nama siger dipakai karena pada sepertiga bagian atas layang-layang memang diberi gambar siger.

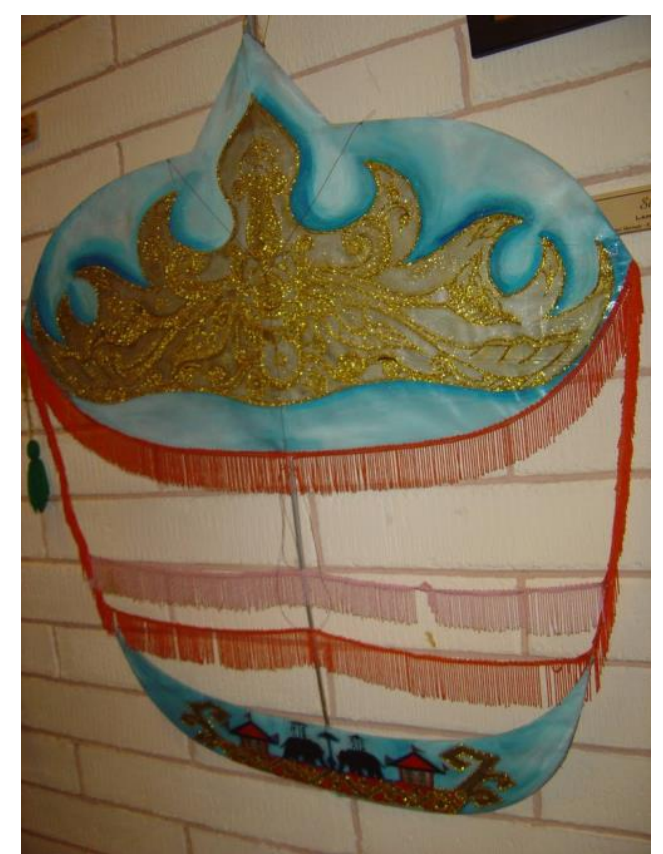

Gambar 5 Layang-layang siger

Sumber: http://intoblackforest.blogspot.com/2006/09/menengok-layang-layang-berusia-4000.html

Tradisi menggunakan layang-layang siger bermula dari kebutuhan nelayan dalam memancing. Layang-layang dimanfaatkan sebagai alat untuk membantu nelayan memancing. Nelayan memanfaatkan kemampuan layang-layang yang dapat diterbangkan jauh dari kapal. Disangkutkanlah umpan untuk memancing di benang yang terbentang jauh terbawa layanglayang siger. Dengan letak umpan yang jauh dari kapal, ikan menjadi tidak takut untuk mendekati umpan. Sama halnya dengan alat pancing yang biasa, jika ada ikan yang memakan 
umpan dan tersangkut maka benang layang-layang siger akan bergetar akibat tarikan ikan yang berusaha melepaskan diri dari jeratan.

Layang-layang siger ini awalnya dibuat menggunakan bahan dari daun loko-loko yang sudah kering dan memiliki rangka yang terbuat dari bambu. Seiring dengan banyaknya pengalaman para nelayan, saat ini penggunana bahan daun loko-loko diganti dengan bahan plastik. Penggantian bahan ini bertujuan agar layang-layang siger tidak cepat rusak akibat terkena air saat memancing.

Penyebaran layang-layang juga sampai ke pulau Jawa. Banyak daerah di Jawa juga memiliki tradisi menerbangkan layang-layang. Salah satu contoh layang-layang di pulau jawa ada di Jawa Tengah. Di sana juga dapat ditemukan layang-layang yang khas, yaitu layang-layang sendaren. Sama halnya dengan layang-layang siger, tradisi layang-layang pepetengan ini muncul karena adanya kebutuhan yang berkaitan dengan mata pencaharian. Jawa Tengah sebagai daerah yang memiliki banyak lahan persawahan diperlukan adanya sebuah cara untuk menghalau burung-burung yang dapat merusak padi.

Penggunaan layang-layang sendaren dalam menjaga sawah adalah dengan dibiarkan terbang melayang di atas sawah. Burung-burung yang hendak mendekati sawah akan merasa takut dan akhirnya tidak jadi hinggap di tanaman padi yang ada di sawah tersebut. Sendaren adalah aksesoris pada layang-layang yang letaknya ada di bagian atas layang-layang. Sendaren pada umumnya dibuat dari bambu yang melengkung dan diikatkan pita kaset yang membentang dari ujung bambu yang satu ke yang ke dua. Sehingga bentuk sendaren ini mirip dengan busur panah.

Sendaren pada layang-layang bisa mengeluarkan suara yang nyaring ketika terkena angin kencang. dari pita yang diregangkan tersebut akan keluar suara Sendaren ini digunakan hanya untuk penghias layang-layang yang mengeluarkan bunyi. Bunyi itulah yang mampu mengusir burung, atau hama di sawah.

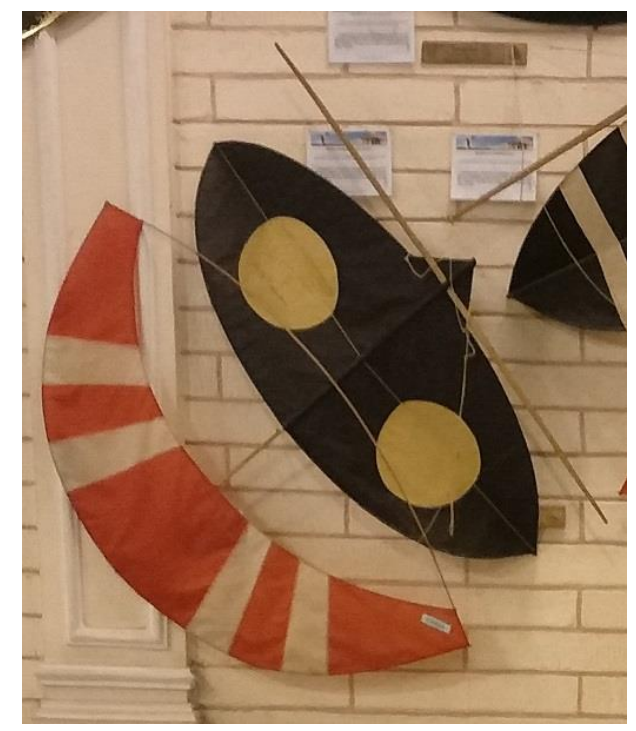

Gambar 6 Layang-layang sendaren

Masyarakat Bali memiliki tradisi unik yang berkaitan dengan layang-layang. Ada satu jenis layang-layang khas Bali yang berukuran sangat besar, yaitu layang-layang janggan. Besar layang-layang janggan mencapai $5 \times 10$ meter. Layang-layang janggan memiliki ekor yang sangat panjang hingga mencapai 100 meter. Di bagian paling atas layang-layang dipasang kepala naga. Ukuran total layang-layang janggan ini bisa mencapai lebih dari 200 meter dan perlu orang 
banyak untuk menerbangkannya dikarenakan ukurannya yang sangat besar itu. Janggan merupakan salah satu layang layang yang digunakan untuk ritual atau upacara adat. Layanglayang janggan disimpan di Pura sebelum diterbangkan menjelang ritual atau upacara.

Berdasarkan data yang dikumpulkan terkait proses perancangan komunikasi visual pengenalan layang-layang sebagai budaya bangsa Indonesia terdapat beberapa temuan yang dapat menjadi acuan dalam merancang. Tradisi bermain layang-layang tak lepas dari peran layang-layang sebagai alat yang membantu masyarakat dalam hal mata pencaharian. Hal ini dapat dilihat dari fungsi layangan yang digunakan sebagai alternatif alat pancing dan alat yang dapat menjaga keberhasilan panen pertanian dengan menghalau berbagai macam hama atau burung. Tradisi penggunaan layang-layang juga banyak dilakukan sebagai wujud ekspresi kegembiraan dan rasa syukur atas hasil panen. Ini tidak lepas dari pengaruh kepercayaan agama yang dianut oleh masyarakat nusantara pada zaman dahulu. Indonesia, seperti di Jawa sama halnya dengan tradisi pewayangan yang mengenal adanya dewa-dewi yang dianggap memiliki kekuatan yang dapat memberi pengaruh pada kehidupan manusia.

Dari hal-hal yang ditemukan di atas dapat katakan bahwa layang-layang memang erat sekali dengan kehidupan masyarakat Indonesia karena tradisi bermain layang-layang bukan saja merupakan sebuah permainan yang menarik dan mengasyikkan, namun memang merupakan kebutuhan baik secara materil maupun spiritual yang menjadikan layang-layang merupakan bagian dari perjalanan hidup masyarakat Indonesia yang berada di negara agraris dan juga dikelilingi laut.

Bentuk layang-layang tradisional di Indonesia terlihat memiliki ukuran yang lebih besar dibanding dengan layang-layang permainan yang biasa dimainkan oleh anak-anak. Hal ini karena memang menyesuaikan kebutuhan untuk memenuhi kriteria sebagai layang-layang yang dapat menjalankan fungsinya baik itu sebagai alat pancing, alat penghalau hama, atau pun untuk menunjukkan keagungan pada sebuah perayaan. Selain memiliki fungsi-fungsi yang telah dijabarkan, melihat berbagai macam bentuk layang-layang yang ada di Museum Layang-Layang Indonesia, layang-layang juga dijadikan sebagai permainan yang dapat dipertandingkan. Agar apat dimainkan oleh anak-anak, banyak jenis layang-layang dibuat dalam ukuran yang lebih kecil dan ringan yang dapat diterbangkan sendiri.

Permainan menggunakan layang-layang ada yang berbentuk seperti olah raga yang dipertandingkan. Ini bentuk permainan yang sering dikenal dengan istilah layang-layang aduan. Bentuk permainnya beragam, yang paling terkenal adalah bentuk aduan yang mencoba untuk saling menjatuhkan. Bentuk permainan aduan lainnya adalah layang-layang yang mencoba menjadi laang-layang yang terbang paling tinggi disbanding peserta lain.

Bentuk permainan layang-layang lain kerap yang dipertandingkan adalah bentuk lomba yang lebih menekankan pada bentuk kreasi layang-layang yang terlihat saat diterbangkan. Dari permainan inilah muncul berbagai macam kreativitas variasi bentuk, ukuran, warna, dan juga bahan seperti beberapa koleksi yang terdapat di Musuem Layang-Layang Indonesia. Banyak nilai positif yang dapat diambil dari permainan layang-layang, terutama bagi para orang tua yang mengajak anaknya bermain layang-layang. Nilai-nilai positif itu antara lain permainan ini dapat mengajarkan dan menumbuhkan sikap sabar, gigih, dan membiasakan mereka unutk kerja sama.

Seiring perkembangan zaman, layang-layang yang sudah menjadi tradisi kini dianggap memiliki potensi wisata karena memiliki daya tarik. Adanya berbagai event dan lomba yang melibatkan permainan layang-layang menunjukkan salah satu cara untuk menarik perhatian dan melestarikan budaya layang-layang tradisional 


\section{Strategi Konsep Perancangan}

Berdasarkan permasalahan dan uraian deskripsi bentuk-bentuk layang-layang tradisional Indonesia, maka konsep perancangan dibuat agar anak-anak memahami konsep permainan layang-layang mulai dari bentuk hingga fungsinya. Pemilihan motion graphics sebagai media komunikasi berangkat dari pemikiran bahwa saat ini, baik anak-anak maupun dewasa sangat dekat dengan telepon genggam. Bentuk desain berupa karya digital dapat memanfaatkan internet agar karya tersebut dengan mudah diterima oleh penggunan telepon genggam. Contoh media yang dapat digunakan adalah media sosial.

Motion graphics memiliki prinsip yang sama dengan animasi yaitu merupakan sekuensial gambar-gambar diam yang mampu membuat ilusi seolah-olah bergerak (Lupton and Phillips). Komunikasi visual berupa konten dalam bentuk media digital motion graphics dapat meningkatkan efektivitas penjelasan secara terperinci (Barnes).

\section{Tujuan Komunikasi}

Tujuan komunikasi pada konsep perancangan motion graphics adalah menceritakan tentang ciri khas bentuk layang-layang tradisional dan apa yang mempengaruhi bentuk layanglayang pada masing-masing daerah dari data penelitian yang ada. Selain itu juga penting untuk menyampaikan nilai-nilai positif dari permainan layang-layang. Adapun pesan dalam konsep perancangan motion graphics adalah untuk mengajak target audience yang sesuai dengan permasalahan. Sasaran utama pesan ini disampaikan kepada anak-anak usia 7-10 tahun dengan sasaran sekunder orang tua muda yang memiliki anak 7-10 tahun. Secara psikografi, pesan ini ditujukan kepada anak-anak yang aktif, gemar olahraga, serta orang tua yang senang beraktifitas dengan anaknya.

\section{Pendekatan Kreatif}

Dalam merancang konsep motion graphics pada penelitian ini, digunakan beberapa kata kunci yang dijadikan acuan visual. Kata kunci yang ditemunkan disesuaikan dengan strategi konsep perancangan. Kata kunci yang dimaksud antara lain Layang-layang, Indonesia, tradisi, dan seru. Pendekatan visual secara rasional dirancang agar target audience mengetahui adanya ragam fungsi layang-layang. Sedangkan pendekatan visual secara emosional dirancang agar dapat menyampaikan pesan berupa nilai-nilai positif dari layang-layang, yakni sabar, gigih, mau kerja sama, dan tak kalah penting menumbuhkan rasa bangga karena di zaman dulu bangsa kita dapat memanfaatkan layang-layang dalam kehidupan sehari-hari.

\section{Pendekatan Visual}

Pendekatan visual yang disiapkan adalah ilustrasi yang diolah dengan proses komputer berupa pengolahan gambar vektor. Teknik ini digunakan agar bentuk yang digambarkan dapat disederhanakan. Hal ini menyesuaikan karakteristik gambar yang dihasilkan oleh anak-anak. Warna-warna yang digunakan adalah warna-warna yang berasal dari warna motif-motif layanglayang yang kerap diaplikasikan. Warna-warna tersebut dipadu padankan dengan warna-warna alam yakni hijau dan biru yang merupakan warna yang memang identik dengan suasana permainan layang-layang. Permainan yang dilakukan di ruang terbuka yang luas dan diterbangkannya layang-layang ke langit membuat palet warna tersebut mampu menampilkan suasana yang dirasakan pada saat bermain layang-layang. Merujuk pada fungsi layang-layang sebagai pengusir hama juga yang dijadikan alat bantu memancing, maka warna-warna yang dipilih sudah sesuai. Warna hijau dapat dirasakan pada saat layang-layang yang diterbangkan di lahan persawahan untuk mengusir hama. Warna biru muda yang digunakan untuk 
merepresentasi luasnya langit dikombinasikan dengan warna biru laut sebagai visualisasi air laut tempat nelayan menerbangkan layang-layang.

Informasi dan cerita yang disampaikan dalam konsep perancangan motion graphics pengenalan layang-layang sebagai budaya bangsa dibutuhkan bantuan berupa tulisan yang dapat dibaca dengan jelas. Sehingga pemilihan tipografi perlu diperhatikan agar memiliki tingkat keterbacaan yang baik. Selain itu tipografi turut membantu membangun suasana sesuai pesan yang ingin disampaikan. Dalam perancangan motion graphics ini suasana yang ingin ditampilkan adalah suasana aktif dan menyenangkan. Jenis huruf yang digunakan adalalah jenis sans serif yang dapat digunakan untuk menunjukkan sifat dinamis permaianan layang-layang.

\section{Simpulan}

Hasil penelitian untuk perancangan konsep motion graphics pengenalan layang-layang sebagai budaya bangsa Indonesia dapat menunjukkan bahwa ciri khas bentuk dan desain layanglayang yang ditemukan di beberapa daerah di Indonesia banyak dipengaruhi oleh fungsi dari layang-layang itu sendiri. Masing-masing daerah memanfaatkan layang-layang dengan cara yang beragam. Ragam fungsi yang ternyata dapat dilakukan dengan baik oleh layang-layang tak lepas dari pengaruh kondisi lingkungan alam.

Upaya mempertahankan tradisi layang-layang sebagai budaya bangsa sebenarnya sudah ada di beberapa daerah seperti di Bali. Namun upaya ini memang tidak diiringi dengan komunikasi yang luas sehingga eksposur layang-layang sebagai budaya bangsa hanya dirasakan oleh masyarakat setempat. Perkembangan teknologi informasi dan komunikasi yang semakin canggih di masa ini memberikan kemudahan untuk mengenalkan kembali pada masyarakat lebih luas terutama generasi muda. Konsep perancangan motion graphics juga menonjolkan manfaat bermain layang-layang yaitu berupa nilai-nilai positif yang dapat ditanamkan diri anak-anak, yakni sabar, gigih, mau kerja sama.

Secara visual, tampilan yang digunakan adalah tampilan yang dapat menunjukkan kekhasan tradisi budaya bangsa Indonesia dengan pendekatan yang dapat diterima oleh anakanak. Dengan konsep yang tepat untuk mengenalkan dan memberikan rasa bangga akan layanglayang tradisional, maka besar kemungkinan masyarakat terutama anak-anak akan lebih menyadari bahwa layang-layang juga merupakan salah satu kebudayaan bangsa Indonesia. Latar belakang terbentuknya ciri khas bentuk layangan tradisional ini pada masing-masing daerah di Indonesia dapat dijelaskan melalui visual pada konsep motion graphics. Unit-unit pada konteks layang-layang masing-masing daera inilah yang akan menjadi unit-unit penyusun visual motion graphics yang dapat dibaca sebagai sebuah makna kolektif bahwa layang-layang merupakan salah satu budaya bangsa Indonesia.

\section{Daftar Pustaka}

Barnes, Spencer. "Studies in the Efficacy of Motion Graphics: How the Presentation of Complex Animation Implicates Exposition." Journal of Entertainment and Media Studies. Vol, vol. 2, no. 1, 2016, pp. 37-76, http://jems.okstate.edu/vol-2-iss-1-march-2016/studies-inthe-efficacy-of-motion-graphics-how-the-presentation-of-complex-animationimplicates-exposition/. 
Collington, Mark. Animation in Context: A Practical Guide to Theory and Making. Fairchild Books, 2016.

Lupton, Ellen and Cole Phillips Phillips. Graphic Design: The New Basics. Princeton Architectural Press, 2008.

Meisaroh, Siti et al. "Layang-Layang Bebean Di Desa Ungasan, Kecamatan Kuta Selatan, Kabupaten Badung." Jurnal Pendidikan Seni Rupa Undiksha, vol. 4, no. 1, 2014, https://ejournal.undiksha.ac.id/index.php/JJPSP/article/view/4256.

Mikkolainen, Terhi. "Fly through the History of Kites." gbtimes 15 Desember 2016 https://gbtimes.com/fly-through-history-kites. Accessed 22 Oktober 2018.

Puspoyo, E.W. . Layang-Layang Indonesia. Museum Layang-layang Merindo kites \& Gallery and Q Communication, 2004.

Udytama, I Wayan Wahyu Wira. "Perlindungan Hukum Terhadap Eksistensi Layang-Layang Tradisional Bali Sebagai Penguatan Pariwisata Budaya." Jurnal Advokasi, vol. 6, no. 1, 2016, pp. 85-94, http://jurnal.unmas.ac.id/index.php/advokasi/article/view/476. 